\title{
Los orígenes del Hotel Villapanés, la semblanza de un gran palacio
}

Isabel Corripio Gil-Delgado

UNED (España) 



\title{
Los orígenes del Hotel Villapanés, la semblanza de un gran palacio
}

\section{The origins of Villapanés, the semblance of a grand palace hotel}

\author{
Isabel Corripio Gil-Delgado \\ UNED (España) \\ icorripio1@alumno.uned.es
}

Fecha de recepción: 17 de mayo de 2017

Fecha de aceptación: 16 de octubre de 2018

\section{Resumen}

El presente artículo versa sobre la historia del Hotel Villapanés que deriva del antiguo Palacio Torreblanca levantado por don Manuel López Pintado a principios del siglo XVIII. En este sentido la investigación de su parcelado, que hemos dividido en dos etapas hasta el año de 1728 y, a partir de él hasta 2012 en que fue rehabilitado, pretende destacar cómo el devenir histórico que se remonta hasta el siglo XI, cuando se documenta una rica vivienda almorávide, juega un papel fundamental en la valoración real de un inmueble a la hora de enfocar su conservación.

Palabras clave: Palacio Torreblanca (Sevilla); Manuel López Pintado; Rehabilitación arquitectónica; Hotel Villapanés (Sevilla).

\begin{abstract}
This article is about the history of the Villapanes Hotel which was originally built as the Torreblanca Palace by don Manuel López Pintado at the beginning of the 18th century. The investigation of its plot, which we have divided into two stages; up until the year 1728, and from then up until 2012 during which it was rehabilitated, aims to highlight how historical development dating back to the 11 th century, when a rich housing 'almorávide' (almoravid) is documented, plays a fundamental role in the actual valuation of a property when it comes to focus on its conservation.
\end{abstract}

Keywords: Torreblanca Palace (Seville); Manuel López Pintado; Architectural rehabilitation; Hotel Villapanés (Seville). 
Los orígenes del Hotel Villapanés, la semblanza... - Isabel Corripio Gil-Delgado

Para citar este artículo: Corripio Gil-Delgado, I. (2019). Los orígenes del Hotel Villapanés, la semblanza de un gran palacio. Revista de humanidades, $\mathrm{n}$. 36, pp. 63-84. ISBN 1130-5029 (ISSN-e 2340-8995).

Sumario: 1. Introducción. 2. Desarrollo. 3. Conclusiones. 4. Bibliografía.

\section{INTRODUCGIÓN}

Acertar en la correcta elección de una casa nunca ha sido tarea fácil, incluso si se tiene claro lo que se desea. Cuando el Almirante Manuel López Pintado decidía a principios del XVIII asentarse definitivamente en la ciudad de Sevilla, necesitaba obligatoriamente un lugar en función de su alto nivel económico y su estatus, dos aspectos que limitaban mucho los sitios donde podía vivir. Las oportunidades en este sentido eran bastante escasas pues las parcelas más exclusivas de la ciudad estaban por lo general ocupadas por las nobles familias que permanecían allí hacía siglos.

Sin embargo, cuando el año de 1726, en el número 35 de la calle Santiago se procede a la subasta de los bienes inmuebles de un noble venido a menos y que no podía pagar las deudas del Servicio de Lanzas, por fin surgía la oportunidad de obtener una parcela acorde con las expectativas residenciales. Los vecinos, y la misma parcela, provenían del linaje de los Ponz y marqueses de Sotomayor, (Vargas, Ponce de León, Alfaro, Padilla), que habían vivido en los números 31-37 de la calle Santiago nada menos que desde el siglo XV, según las escrituras notariales del Archivo Villapanés ${ }^{1}$, posteriormente: A.V., y del Archivo Histórico Provincial de Sevilla, posteriormente: AHPSE. De este modo, el Almirante podría instalarse en una zona de abolengo y tranquila al lado del convento de monjas dominicas Nuestra Señora de los Reyes, en una vivienda que además tenía la particularidad de haber sido antes del rey de Baeza llamado Abdelmán ${ }^{2}$, uno de los 200 caballeros que acompañaron a Fernando III el Santo en la conquista de Sevilla.

Más allá de estos datos, la construcción incluso podía remontarse hasta el siglo XI, siendo considerada una de las primeras casas musulmanas de alto rango conocidas, lo que ya era indicio de la categoría del lugar y el cuidado con el que se miraban las propiedades privadas. En este sentido, encontramos un proceso de conservación y continuo ejercicio de mejora de las élites, que antecede lo que hoy en día significa la preservación. Derivada de una vieja obligación familiar caracteriza

1 Las escrituras de la casa de Santiago han sido obtenidas del Archivo de la familia Villapanés en la parte correspondiente al sector Torreblanca que es el atado VI. Nuestra más cordial gratitud al Excmo. Sr. D. Hugo O`Donnell, Duque de Tetuán, administrador del Archivo Villapanés por todas las facilidades que nos ha dado.

2 Basándose en el repartimiento de Sevilla de Argote de Molina (p.225), la memoria históricoarquitectónica del convento de las Descalzas Reales, antes, Santa María de los Reyes (1988, p.4) indica la posibilidad de que estas casas fueran las que estaban lindando con el convento. 
todo el periplo de la vivienda, incluso en el momento de derribar un inmueble y levantar otro encima. El cuidado con que el nuevo palacio Villapanés, erigido por Manuel López Pintado, sigue la misma línea de integración espacial y social, es el mismo que hoy subyace en el hotel de cuatro estrellas que lo conserva. Que siga llamándose Villapanés (S.XIX) y no Torreblanca (S. XVIII) o palacio de Abdelmán (S. XII), es síntoma de que aún pervive ese interés hacia un pasado, aunque este sea en la aristocracia más próxima, es decir, siempre en el mismo nivel.

Por tanto, el artículo sobre los orígenes del hotel Villapanés se presenta para poner sobre la mesa el sentimiento de apego histórico como medio de paliar el olvido en el que decaen estos inmuebles fuera de su consideración artística. Hay que destacar la importancia que la evocación al pasado tiene en todo proceso de preservación y conservación que se precie es el objetivo fundamental de estas líneas.

\section{DESARROLLO}

2.1. Primera etapa: el devenir histórico del palacio Villapanés y Torreblanca hasta el siglo XVIII.

La casa de los López Pintado, conocida desde el siglo XIX como palacio Villapanés por su asociación a la familia Duque de Estrada, está ubicada en el actual número 31 de la calle Santiago dentro de la manzana de casas que conforman el parcelado de las calles Santiago, Ave María y Azafrán.

Esta zona, que, en la época romana y por ser extramuros, estaba destinada solamente a labores agrícolas, había experimentado pocos cambios hasta la Edad Media que se urbanizó con los primeros asentamientos externos a la muralla en la prolongación de sus vías Cardo y Decumano. De hecho, la aparición de restos arqueológicos como fueron un molino y distintos aperos de labranza propios de las culturas romana y visigótica, demuestran que era zona de extrarradio.

A partir de aquí, el Informe de Intervención Arqueológico de las Descalzas Reales realizado por Pablo Oliva y Miguel Ángel Tabales ${ }^{3}$, calcula que fue en el periodo almorávide del siglo XI, cuando se produjo la construcción de una cerca mayor que discurriendo por la calle Muro de los Navarros dejó la zona de Santiago intramuros. Al quedar su situación determinada entre las puertas del Osario al Norte, Carmona al Sur y la vieja de Santa Catalina al Oeste, esta zona pasó a formar parte de

3 Manuel Salas de la Consejería de Fomento y Vivienda de Sevilla, el año 2012 nos permite el acceso al original de la memoria histórico-arquitectónica de las Descalzas Reales, antiguo convento de Santa María de los Reyes cuyo análisis arqueológico lo firman Pablo Oliva y Miguel Ángel Tabales el año de 1988. (p. 4). Nuestra más cordial gratitud a Miguel Ángel Tabales por todos los documentos arqueológicos que nos ha facilitado en relación con el palacio Villapanés. 
la zona elitista que se establecía en el entorno de la Mezquita Aljama, actual Catedral de Sevilla (Chueca, 2001, p. 389) ${ }^{4}$.

Es precisamente en esta fecha, cuando el Informe de Intervención Arqueológico del palacio Villapanés realizado por Rocío López Serena y Manuel Vera Reina (López y Vera, 1998, p. 25) documenta en ese enclave la existencia de una importante edificación de 285 metros, posiblemente propiedad de un rico comerciante, que construyó una vivienda conformada por tres salas paralelas con acceso únicamente desde la habitación central. Para entrar en ella, había que recorrer un pasillo alargado y de unos $80 \mathrm{~cm}$ de ancho, que, como estaba en ángulo (eje acodado), demoraba sustancialmente el tiempo de acceso a la gran sala central y a las habitaciones que quedaban ocultas a la vista ${ }^{5}$.

Sin embargo, a principios del siglo XII la edificación fue objeto de una importante remodelación y se dividió en dos partes, la Casa Norte $(105 \mathrm{~m})$ y la Casa Meridional (180m), pero, como ambas siguieron unidas por el acceso y la puerta sin grandes cambios en este aspecto, se constata la pervivencia de la misma estructura de estancias entorno a un patio, que, con galerías en dos frentes, servía de paso.

Según el informe, parece ser que esta división permaneció mucho tiempo sin alteraciones, ni siquiera cuando en 1246, con la llegada de los cristianos y Fernando III el Santo, se produjo el repartimiento de la ciudad. De hecho, hacia 1257, como indica Diego Ortiz de Zúñiga, (1796, pp. 67- 172), Alfonso X el Sabio, dio estas dos casas conjuntas al rey moro de Baeza Abdelmán, así como las colindantes fueron a parar a la Iglesia de Santiago y, "las otras cercanas" a Lope Ortiz, Alonso García de Madrid, Domingo Gutierre Solorzano, Juan de Mendoza, Rui García de Trebello hijo de Garcí Garcés y a Martín Meléndez de Forniellos ${ }^{6}$.

De todas ellas vamos a destacar dos: las que fueron propiedad de la Iglesia de Santiago el Viejo, y las del rey Abdelman. Las primeras, situadas en el número 33 de la calle, como indican los documentos notariales del AHPSE (P-5190, 1727, p. $180)^{7}$, se utilizaron durante muchos años como cárceles de la Inquisición y pasado

4 Según Chueca (2001), en general, las ciudades amuralladas suelen experimentar un crecimiento radiocéntrico hacia las puertas de la muralla

5 Este documento de Intervención Arqueológica Preventiva en el inmueble de calle Santiago $\mathrm{n}^{\circ} 31$, antiguo palacio de los marqueses de Villapanés y Torreblanca, es el original realizado por Rocío López Serena y Manuel Vera Reina, facilitado por Miguel Ángel Tabales.

6 Diego Ortiz de Zúñiga, (1796) establece el repartimiento del distrito de Santiago entre varios caballeros indicando que las destinadas a Marín Meléndez Forniellos estaban contiguas a la de Lope Ortiz y al del hijo del rey moro de Baeza que era Fernando Abdelmón. En virtud de ello y de que las escrituras notariales del AHPSE, certifican las colindantes como las pertenecientes a la iglesia de Santiago desde esa fecha, se establece la gran probabilidad de que realmente esa fuera la casa del rey de Baeza Abdelmán.

7 Estos documentos indican textualmente que tiene unas casas pequeñas "que compró a la dicha parroquia de Santiago que primero fueron cárceles de la Inquisición" y que luego se fueron arrendando hasta el siglo XVIII en que figura Baltasar Crespo como último arrendador. 
el tiempo se dieron en alquiler hasta el año 1727. Sin embargo, las que se dicen pertenecientes al palacio de Abdelmán, es decir los números 35 y 37 de la calle Santiago hasta Ave María y que coinciden de manera precisa con las anteriormente referidas casas Norte y Meridional, pasaron a la familia Ponz de la Cámara.

La relación que las escrituras públicas del archivo Villapanés (A.V.) establecen con este linaje se remontan al año 1445, cuando Catalina Ponz de la Cámara, si bien traspasaba el inmueble a su hijo como adelanto de la legítima para que contrajera nupcias, pronto lo recuperó el 28 de septiembre del año de 1446 a la muerte de este sin descendencia. Como ella tampoco tenía otro heredero acabó por venderla a Juan Conde de Niebla por un precio de dos doblas de oro castellano, que recibió el día 24 de abril de 1448.

Este, la utilizó dos años después para pagar los servicios de Pedro de Fuentes quien la conservó hasta el día 2 de junio de 1483 en que fue devuelta a don Pedro

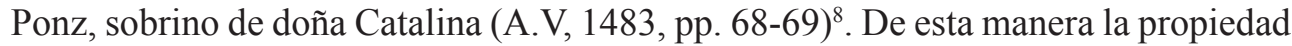
regresa al linaje de los Ponz, siendo Alonso Ponz en 1516 y casado con la distinguida Leonor de Ayala, el quinto titular del inmueble que tenía cinco hijos, todas mujeres.

Por aquél entonces, Sevilla, que se iba configurando como una de las ciudades más prósperas y cosmopolitas de Europa, sentía ya las influencias renacentistas, que encaminadas a organizar el entramado urbano propiciaban una alineación de calles y apertura de espacios. El deseo de abrir ventanas hacia el exterior se decantó en esta ciudad por agrupar y fusionar varias viviendas musulmanas a través de los jardines para poder establecer la mayor parte de las habitaciones de cara a la calle y alrededor de dos patios interiores en dirección norte-sur, o bien, este-oeste (Urquízar Herrera, 2001, p. 203) .

En este contexto, Alonso Ponz reunifica la vivienda en el número 35 a través de una reestructuración que, según el Informe Arqueológico, (López Serena y Vera Reina, 1998, p. 24), consistió en introducir entre los dos jardines de la Casa Norte y Casa Meridional, una habitación de diez por doce metros que contaba con un pasillo de diez metros. Así, este bastimento, que por otro lado dejó gran parte del muro sobresaliendo en desnivel y forma de quilla hacia la esquina Ave María-Azafrán, se convirtió en nexo de la unión entre ambos.

Sin embargo, al fallecimiento de Leonor Ayala, cuando la vivienda pasa a ser propiedad de las cuatro hermanas aún solteras: Luisa, Antonia, María e Isabel de Ayala Ponz, resultó que la quinta, que era la mayor, Beatriz Ponz, y que había casado con el Veinticuatro Pedro de Vargas Sotomayor pensaba en el inmueble para su hijo.

8 Estos documentos de escritura pública de venta y cesión de los archivos de la casa Torreblanca desde 1445 hasta 1483 los encontramos en el Archivo Villapanés, sector Torreblanca, atado VI/1.

9 Urquízar Herrera hace hincapié en el hecho de que a mediados del quinientos la tradición arquitectónica se organizaba a partir de dos patios correspondientes a cada una de las dos viviendas anexadas. 
Si a esto se le une el hecho de que al lado habitaba el hermano de su marido, Alonso de Vargas, que precisamente se había casado con su vecina Beatriz Ponce de León, se comprende el interés por perpetuar la propiedad.

De este modo, el año de 1580 (A.V., p. 69), se llega a un acuerdo por el cual Pedro de Vargas Sotomayor adquiere la propiedad junto con otros bienes, con los que fundó el 11 de agosto de 1608, un mayorazgo (Clavero, 1974) vinculante para su primogénito Juan de Vargas Sotomayor Ponz y que se había casado con Luisa de Padilla en 1592. Para darle mayor valor, decidió incorporar agua corriente, realizando unas obras de adecuación para la instalación de cañerías y depósitos (A.V., 1608, p. $70)^{10}$.

Mientras tanto, con fecha de 1635, se construye muy cerca, en el número 29 de Santiago, el convento de monjas dominicas dedicado a Nuestra Señora de los Reyes, lo que revalorizó mucho el entorno. Por aquél entonces, la casa de Abdelmán pasaba a Alonso de Vargas Sotomayor Padilla, que el año de 1674 deja el mayorazgo a Francisco de Vargas Sotomayor y Guzmán.

Cuando Francisco de Vargas Sotomayor y Guzmán, nombrado marqués de Castellón en 8 de diciembre de 1679 y nacido en 1609, heredaba el mayorazgo en el año de 1664, ya tenía 55 años, y cuando en 1674 recuperaba la administración total de la capellanía le nacía el primero de los dos hijos, Alonso y Francisco que tuvo de su matrimonio con Isabel Rodríguez Alfaro nacida en 1652. Antes de casarse y también con la intención de aumentar el caudal de agua, hizo en 1670 una renovación integral de toda la instalación incluidos almacenes, depósitos y cañerías (A.V., 1679, p. 75).

Poco después, su hijo Alonso de Vargas Sotomayor y Alfaro, segundo marqués de Castellón, que tuvo diez hijos con Teresa Rivera y Tapia Avendaño, sometía la casa a una importante remodelación estructural en dos fases (López y Vera, 1998, p. 24-25). La primera, que fechada en 1699 iba encaminada a elevar el número de dependencias, se desarrolló eliminando las divisiones a lo largo de dos pasillos en sentido norte sur del patio. Abierto sólo en esos dos frentes, se cerraba en los costados este y oeste a través de dos crujías longitudinales donde se colocaron estancias en la misma disposición. Para articularlo mejor se estructuró una gran puerta de comunicación en la mitad de la galería norte que daba paso a un precioso jardín de crucero y que limitaba los cuartos de la medianera del norte con la casa que daba a la calle Azafrán.

La segunda fue el año 1703 y consistió en la ampliación de los límites parcelarios más allá de la vivienda, a costa de la casa de sus vecinos y familiares los Vargas Ponce de León y que provenía de la herencia de Juana Padilla. Cuando en ese año, Francisco de Vargas Sotomayor Avendaño, tercer marqués de Castellón, solicitaba

10 Esto se establece en función de la copia de la escritura de agua de pie que disfruta la casa principal de la calle Santiago número 37 y que aparece fechada el 7 de julio de 1607 en la página 70 correspondiente al atado VI/1 del Archivo Villapanés, sector Torreblanca. 
el permiso para ocupar parte del número 37 (antiguo 39), en base a su numerosa familia, lo que hizo fue retranquear el muro medianero de la parte oeste y añadirle una puerta de acceso (A.V., 1728, pp.1-10).

Sin embargo, cuando a consecuencia del coste de la obra se produjo el endeudamiento del marqués, el no poder hacer frente a los pendientes generó en 1723 la liquidación y subasta de parte de sus bienes entre los que se incluían esta casa. Es en 1726 cuando se concreta la venta del edificio a favor del Almirante Manuel López Pintado ${ }^{11}$ que la adquirió por desgracia ya bastante deteriorada y con obligación de derribarla entera. Como en el momento de realizar los contratos legales y firmar escrituras, ocurriera que el anexo de los Vargas Ponce de León no le pertenecía ${ }^{12}$, don Manuel tuvo que adquirir aparte esa porción de la vivienda, aspecto que se solucionó en 1727 con la compra de toda la propiedad correspondiente al número 39, nuevo 37, que incorporaba así al $35^{13}$.

En vista de esto, también aprovechó para adquirir del lado este, las viviendas que la parroquia de Santiago tenía en el número 31 y que estaban pegadas al convento de Nuestra Señora de los Reyes justo enfrente del campanario de la iglesia, así como la parte del convento correspondiente al frente de la plazuela de la dicha iglesia, que se correspondía a la vieja cocina y lavaderos del 29. Para incluirla, simplemente retranquearon unos metros del muro de separación entrambas hacia la derecha.

\subsection{Segunda etapa: el devenir histórico del palacio Villapanés y Torreblanca en el siglo XVIII.}

Parece ser, que el primer encuentro con el arquitecto Diego Antonio Díaz se produce al hilo del dictamen oficial de la casa subastada. Entonces, se concretó un acuerdo de construcción que duró más de 15 años y que se centraba en un estudio y valoración previo de la vivienda del marqués de Castellón (A.V., 1726, pp. 1-93) ${ }^{14}$,

11 La venta de las casas en Santiago 37 pertenecientes al marqués de Castellón se hicieron el año de 1726 según la documentación del atado VI/1 del Archivo Villapanés, sector Torreblanca. En él aparece relatado todo el proceso de remate con sus llamamientos y pagos, así como la entrada del nuevo dueño en la parcela.

12 Entre los papeles del archivo Villapanés, aparece un recurso presentado por don Jacinto Serrano en 1731, que en función del derecho a la parte proporcional de su vivienda supone el origen de las futuras desavenencias entre el Almirante y don Jacinto Serrano, otro vecino con derechos sobre la misma parcela y cuyos desencuentros se prolongarían hasta 1739 fecha del fallecimiento de este último.

13 En el año de 1735 otro pleito encontrado en el archivo, del atado VI/1 pág. 145v, por las casas principales pertenecientes a don Manuel López Pintado inciden en la trampa que subyacía con las propiedades vinculadas, y es que el marqués de Castellón declaró ilícita la venta argumentando una vinculación para recuperar la vivienda. Este hecho no era desconocido entonces y muchas casas se recuperaron de este modo, aunque en este caso se desestimó la demanda.

14 En este documenta se indica todo el proceso de compra de la vivienda fue tasada y vendida en 35.500 reales de vellón que se pagaron en mano. 
al que luego se sumó el de las otras parcelas: las casas pequeñas pertenecientes a la parroquia de Santiago el Viejo, que valoró y aconsejó pagar 5.000 reales de vellón en 17 de junio de 1726 (A.V., 1727, p. 180) ${ }^{15}$, la parte del convento de religiosas de Nuestra Señora de los Reyes (AV., 1727, p. 1-15) ${ }^{16}$ y, la que quedaba de la vivienda de los Vargas Ponce de León y Jacinto Serrano, cuyo precio tasó sólo en 14.118 reales de vellón (AV., 1728, p. 526) ${ }^{17}$.

También aquel año de 1727 se pretendía una última parcela correspondiente a su vecino Juan José del Castillo y que llegaba hasta el número 33 de la calle Santiago. Sin embargo, las negociaciones, que duraron desde 1727 hasta 1739, sólo lograron una pequeña parte de la casa, la correspondiente al frontal de la calle Santiago (AV., 1739$, p. 24$)^{18}$, que sirvió para ampliar la parcela en la fachada, establecer la superficie definitiva estimada en 4.175,57 metros cuadrados, y acabar con la edificación del rey de Baeza Abdelmán.

Por entonces, había en Sevilla dos corrientes arquitectónicas que se superponían en una especie de duelo estilístico (Ollero, 2005, p. 119). De un lado, las extravagancias barrocas eran ya muy criticadas (Ponz, 1972, pp. 205-211) y del otro se reclamaba el retorno a un refinamiento de líneas regulares clásicas ${ }^{19}$. Y es que el descubrimiento de Herculano y Pompeya hacía que los arquitectos se inspiraran en un Vitrubio, cuyos "Diez Libros de Arquitectura" (Sanz y Sanz, 1992), nunca habían dejado de ser en Italia el modelo a través del cual establecer el grado de poder de los edificios y sus moradores (Rodríguez Ruiz, 1992, p. 15). De hecho, la inclinación de las ciudades a una nueva expresividad civil y doméstica (Ollero, 2005, p.119) que recordara los templos griegos y las construcciones romanas (Kostof, 1988, p.984) era el ambiente que los maestros de obra debían tener en cuenta sobre todo para aquellas edificaciones nuevas públicas y privadas.

15 La compra de esta vivienda a la parroquia de Santiago el Viejo se concertó a través de una permuta que se hizo por otras casas que el Almirante tenía al principio de la calle Enciso.

16 En este caso (Torreblanca: 1727, p. 1-15), la parte del convento contigua al palacio era la correspondiente al lavadero y cocina que a cambio se rehízo totalmente con un paso añadido entre la ambas.

17 Después de todos los problemas que había tenido con la parte perteneciente a los Vargas Ponce de León (Torreblanca: 1728, p.526), el Almirante se decide a adquirir el resto de la dicha vivienda concretándose una venta efectiva por importe de 14.118 reales de vellón. Este acuerdo lo concretó el tutor Jacinto Manuel Serrano en nombre de sus hijos los Serrano Vargas Ponce de León que eran menores.

18 Diego Antonio Díaz declaró textualmente que la dicha casa estaba sirviendo como cochera y que no sólo habría que desincorporarla, sino también incorporarla a las casas del Almirante con un corredor alto en el zaguán de una casa que encima estaba ruinosa tanto en la parte alta como en la baja y era necesario reedificarla de nuevo.

19 Cómo indica Delfín Rodríguez Ruiz, la construcción de una Arquitectura de la Razón es entendida como una meditación sobre el clasicismo, pero haciendo confluir modelos renacentistas y barrocos con imágenes arqueológicas y racionalistas. 
Estas cuestiones se reforzaban en los enclaves de mayor importancia y con objeto de armonizar la perspectiva visual, se empezaba a descartar la innovación personal, lo cual era un síntoma del rigor que se sentía en el neoclasicismo (Bonet, 2011, pp. XLVII-LII). Esto lo sabía bien el Almirante López Pintado, que además de comerciante (Cádenas, 1976, p. 20), militar, rico e hidalgo, era un hombre de gustos refinados y mecenas (Tapias, 2015, p.88). Él, cómo ilustrado, abanderaba los nuevos parámetros estructurales a los que tendía el Estado: someterse a la linealidad de la calle, distribuir las estancias ordenadas según el trazado del patio, dotar de mayor amplitud las portadas para el "interaccionismo social" (Martínez, 2008, pp. 30-31), y establecer en base a ello una decoración más sobria. (Ezquiaga, 1990, p. 386).

De entre ellos ${ }^{20}$, uno de los más destacados era Diego Antonio Díaz. De él se sabe que había nacido en Sevilla en el barrio de San Lorenzo el día 10 de noviembre de 1667 y que, comenzando como albañil en las obras de la iglesia de Nuestra Señora de la O, en el año de 1705 ya era Maestro Mayor de Fábricas de la Ciudad. El cargo, que ostentaría durante 36 años (Lázaro,1988, p. 9-11), precisamente consistía en llevar el control del ornato y adecuación a través de un informe de valoración positivo o negativo según se ajustara o no a las normas urbanísticas (Ollero, 2012).

Diego Antonio Díaz, que murió a la edad de 80 años, el 28 de abril de 1748, es considerado hoy como una pieza clave de la evolución del barroco sevillano, en función de su estilo a caballo entre el más decorativo de Leonardo de Figueroa y el rígido academicismo neoclasicista de finales de siglo ${ }^{21}$ El, no sólo descartó definitivamente la piedra típica renacentista para la construcción de edificios, sino que decidió recuperar el uso del barro cocido para los muros que irían enfoscados haciendo una estructura muy sólida en consonancia a lo que ya dijera el Regente de Andalucía Manuel de Torres para la Real Fundición de Cañones en 1720: "Que, aunque sea con algún mayor gasto, sea la obra sólida en la mejor forma y disposición que sea posible...para que trabajen con gusto y se logre también al más puntual servicio de S.M. ${ }^{22 " \text { ". }}$

De este modo cimentó para la casa Villapanés unos muros de 50 centímetros de espesor con ladrillo de junto para la solería y, ladrillo limio, (limpio o cortado) para los alzados, de 1,5 centímetros colocado a tizón como era su costumbre, que unía con tendeles de $2 \mathrm{~cm}$ e intersticios de 1.5 centímetros recubiertos con mortero de

20 Según Pleguezuelo, (1982, p. 28), en 1762, el maestro Francisco Escacena cifraría el número de maestros de obras en 112, en 80 el de oficiales, 560 de peones y 30 aprendices.

21 Lázaro Muñoz (1988, p. 9-11) relata como este arquitecto estuvo aquejado de una enfermedad que le atacó las manos y se vio muy dificultado para seguir trabajando los últimos años de su vida.

22 En el año 2001 Roig del Negro (2001, p.44) especificaba como para la Real Fundición de Cañones de Sevilla se pretendía una edificación sólida y lo mejor estructurada posible en vistas a la comodidad y a la estabilidad de todos los edificios en general, privados y, públicos. 
cal mortecino (Macías, 2002, pp. 4-5) ${ }^{23}$. Conformados a modo de grandes paneles lisos, reservaba los motivos ornamentales nada más que para reforzar la portada y la bóveda de la escalera a las que dotaba brillantes resaltes compositivos a base de filetes y baquetones, formas caprichosas de curvas, contra curvas y ángulos rectos. Precisamente estas características del aristamiento de la portada y la sobriedad del ladrillo "en limpio" o en "limio" fueron las que habían llevado a Teodoro Falcón Márquez, (2012, p. 150), a concluir como también apuntara antes Antonio Sancho Corbacho (1984, p. 15), que la casa Villapanés había sido levantada por este arquitecto notable.

Así, Diego Antonio Díaz, ferviente seguidor de Leonardo de Figueroa (Lázaro Muñoz, 1988, pp. 9-11), desarrolló un espacio en sentido volumétrico, es decir, no sólo a lo largo, sino a lo alto y ancho del patio que para el efecto necesitaba alinearse correlativamente con la entrada. Como para ello era obligatorio reducir ostensiblemente el viejo apeadero y eliminar su muro de acceso, se produjo un adelantamiento de toda la vivienda y se dejó espacio suficiente para que colocando el jardín en la última crujía del fondo se aprovecharan todos los salientes de la parcela entre calles Ave María y Azafrán de los que no se retranqueó ni un milímetro como se puede observar en figura 1 .

Así, la sensación era la de un eje portada-patio que se abría a la vista general, a través de una fachada principal básicamente lisa y dividida en módulos regulares sucedidos a ambos lados de la portada de acceso con una división horizontal en dos cuerpos con secuencia de ventanas y balcones. Al perimetrar verticalmente la fachada en ocho cuerpos, la gran puerta de entrada quedaba integrada al nivel de los cuartos del piso bajo, pero con un dintel de baquetones aristados en relieve y escudo que se convertía en marco de un patio elevado a modo de estrado sobre cinco peldaños. Su aspecto, abierto en los cuatro frentes al que daba paso otra arcada monumental de tres vanos con relación a dicha portada, contrastaba con la austeridad exterior.

Como el interior debía corresponderse a la monumentalidad indicada por Molina Recio (2011, p. 68), es decir, a la individualización ${ }^{24}$, se estipuló entorno a un patio tradicional, pero ya de aspecto clásico, es decir, con galería de arcos en medio punto doblados en el intradós y trasdós que se apoyaban en columnas de mármol claro sobre basa cuadrada. Pese a que eran de estilo compuesto con doble cimacio, presentaban variantes en el ábaco y sustentaban a modo de entablamento corrido, un arquitrabe de platabandas lisas con friso también liso y cornisa en tono marrón claro, sobre el cual las arquerías del segundo y tercer piso de columnas eran

23 En el mismo sentido del comentario anterior se comprende que el inmueble se levante lo más sólidamente posible, siendo esta estructura de ladrillo cortado que caracteriza el entramado del palacio Villapanés, la que da mayor solidez al edificio.

24 Dentro del largo camino hacia el individualismo la monumentalidad de una vivienda era utilizada por los comerciantes enriquecidos en el sentido icónico de perpetuación nobiliaria, es decir el de permanencia en un lugar durante varios siglos. 


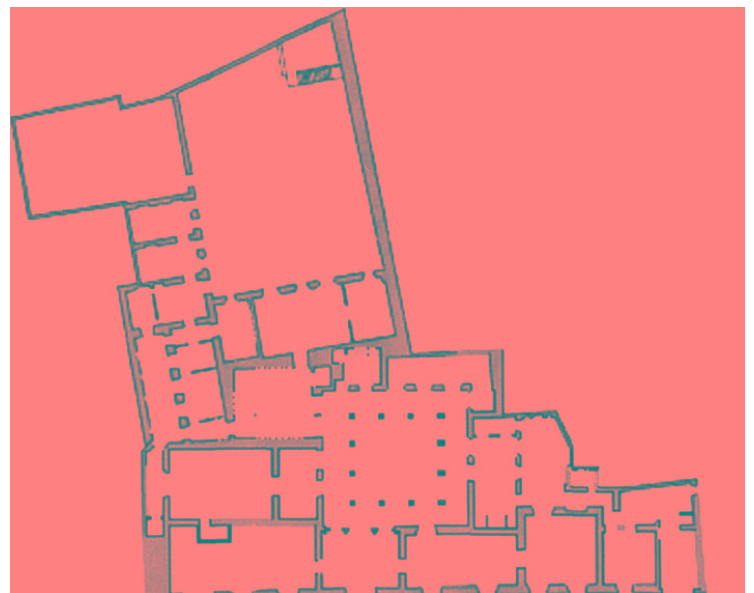

Fig. 1. Planta palacio Villapanés. Guillermo Vázquez Consuegra, (1988, p.41)

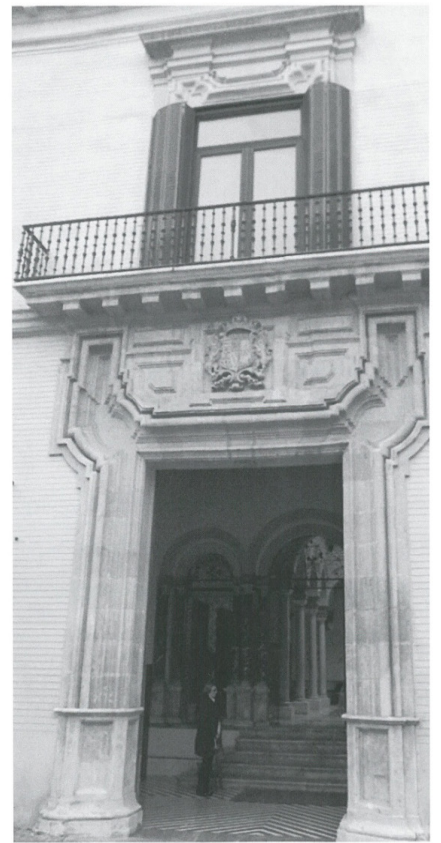

Fig. 2. Puerta de entrada del palacio Villapanés. Fotografía, Isabel Corripio Gil-Delgado.

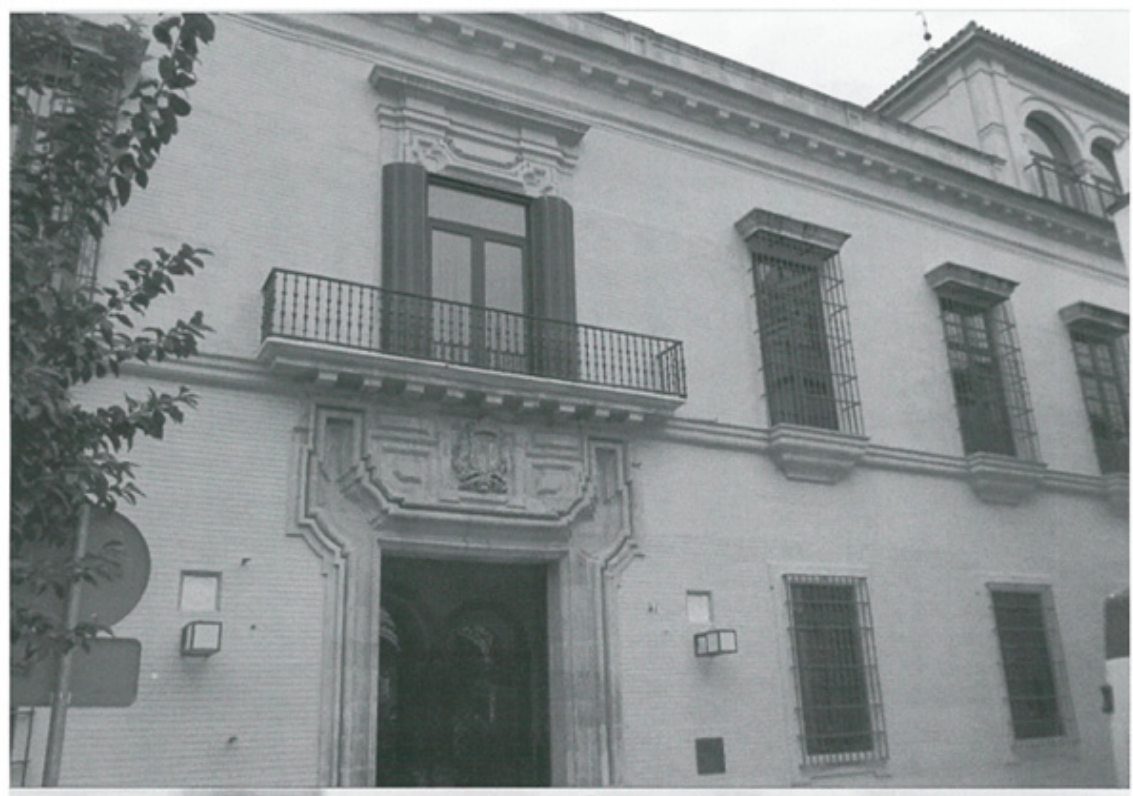

Fig. 3. Fachada del palacio Villapanés. Fotografía, Isabel Corripio Gil-Delgado. 
dúplices y tríplices y en distinta escala. La perspectiva, que asume los tres aspectos de la construcción (León y Sanz 1994, pp. 765-766), se rigió por la fuente central en mármol y de un solo plato, con la figura de un niño, que jugando con un pez tiene el surtidor en la boca y que Teodoro Falcón (2012, p. 153) fecha ya en siglo XIX

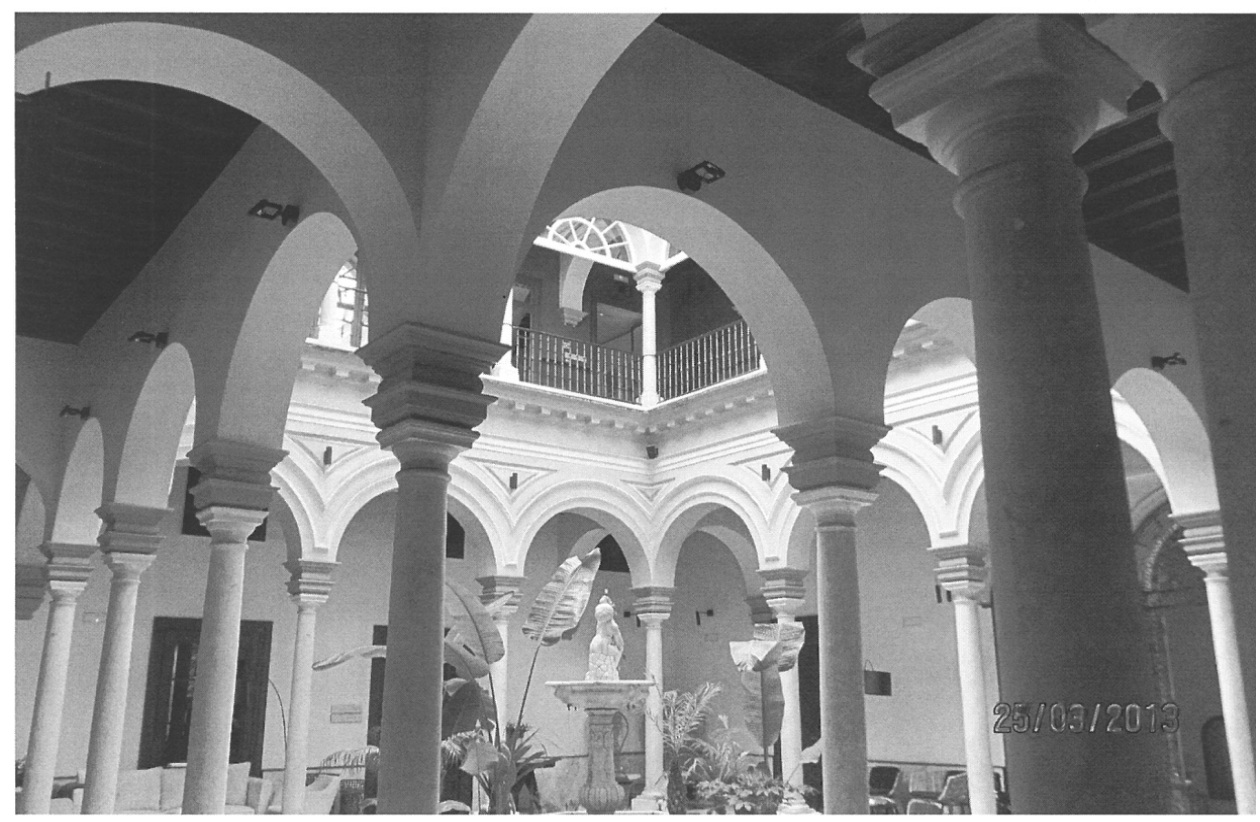

Fig. 4. Patio del palacio Villapanés. Fotografía, Isabel Corripio Gil-Delgado.

A la izquierda de dicho patio, la escalera de mármol de un solo tiro y tres tramos, con pasamanos de caoba, a la que se accedía a través de un gran arco de medio punto, llevaba a las dependencias correspondientes de la primera planta que eran las mismas que la baja. Para reforzarla, el arquitecto usó del sistema abovedado en la caja que, a diferencia de la galería y entresuelo, de arista con plementería a sardinel (Macías: 2003, p. 11), dispuso su tradicional planta de cajón con bóveda de cajón entablada de madera y ricamente tomada y adornada en sus esquinazos con figuras en yeso color blanco y oro, y lunetos separados por arcos fajones (Lázaro, 1988, pp. 9-11).

Como podemos observar, aunque todo indica el abandono definitivo del trazo mudéjar en detrimento de las líneas neoclasicistas, sin embargo, este se hizo perdurar en la estructura tradicional en torno a un patio, y los abovedamientos de arista de la bodega, que se conservaron de la primitiva construcción original almorávide según indica el Informe de Inspección Técnica de Manuel Macías Bernal (2003, p. 11). 


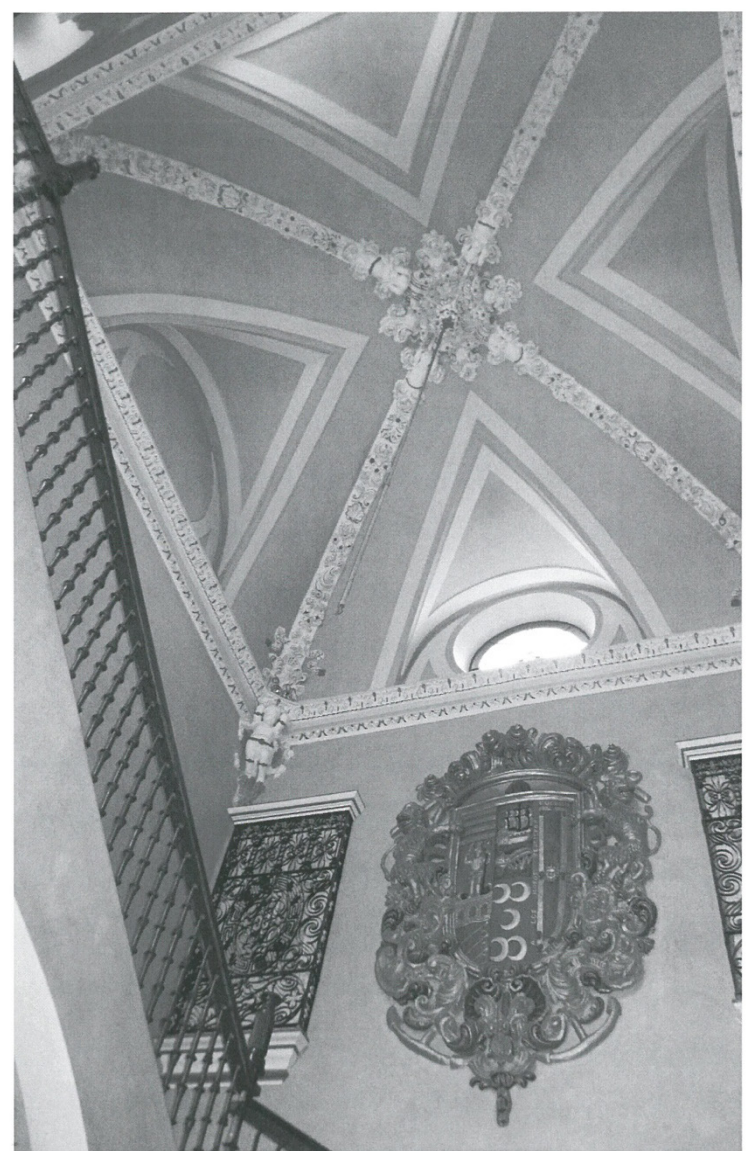

Fig. 5. Bóveda de cajón en la escalera del palacio. Fotografía, Isabel Corripio Gil-Delgado.

A partir de aquí se inicia otro periodo de conservación que se perpetúa durante la sucesión del linaje López Pintado (marqueses de Torreblanca) sin ninguna modificación extraordinaria en Manuel José López Almonacid Pintado Solano, nacido en 1710 y segundo marqués de Torreblanca, Fernando José López Almonacid Pintado y Medina, tercer marqués de Torreblanca, José Manuel López Almonacid Pintado y del Pozo Echevarría como cuarto marqués y María de las Nieves López Pintado Resinas, casada con Juan Antonio Duque de Estrada y González Sepúlveda marqués de Villapanes y quinto marqués de Torreblanca que no tuvo herederos.

A partir de aquí es cuando se pierde la vinculación con apellido López Pintado para ligarse al de Duque de Estrada, en la cabeza de Juan Antonio nacido en Utrera el 15 de enero de 1802 cuando, tras el fallecimiento de María de las Nieves López Pintado, el viudo marqués de Torreblanca y Villapanés, contrajo segundas nupcias 
con Carmen Cabeza de Vaca y Diosdado el 31 de marzo de 1815 de la que nació Juan Antonio Duque de Estrada y Cabeza de Vaca. De este modo, cuando el 31 de marzo de 1882, manda heredar el mayorazgo de Torreblanca, no a su hijo Juan Antonio Duque de Estrada y Cabeza de Vaca, sino a su nieto, Juan Antonio Duque de Estrada y Moreno (Registro de la propiedad 1998, p. 7995) ${ }^{25}$, la casa Torreblanca, pasa a ser la de Villapanés hasta la actualidad.

2.3. Tercera etapa: el devenir histórico del edificio en el siglo XXI, la rehabilitación del palacio Villapanés.

De esta manera el linaje López Pintado se introduce en el devenir histórico de la zona con el de los antiguos marqueses de Castellón y aunque mantener la vivienda, significaba establecer la misma línea de cuidado y protección que sus antecesores, un desafortunado descuido provocó el deterioro y desmoronamiento de parte de la portada de la fachada principal a la calle Santiago el año de 1997 con el subsiguiente llamamiento público de hacer un informe técnico de la situación real del inmueble. El Informe de Inspección Técnica, redactado por Manuel Macías Bernal (2002) ${ }^{26}$, establecía una rehabilitación cuyo coste estimó el constructor, Ramón Marqués de Riancho, en 927.432,16 euros el mismo año ${ }^{27}$.

Así, en 2004, la familia decide vender el inmueble en 140 millones de pesetas a la familia Arnau que al poco la revendió a Joaquín Saucejo representante del grupo DIDRA. La propiedad actual según la escritura de compraventa fechada el 29 de enero del año 2004, firmada ante el notario Antonio Ojeda Escobar, y corroborada por el documento tomado del Registro de la Propiedad de Sevilla $\mathrm{n}^{\circ}$. 11, asiento 49/191, certifica que está en manos de tres sociedades: la 3491 MA. SL con CIF: B 8133 0243, que posee el $40 \%$ del inmueble, la 49PVS.L, con CIF $n^{\circ}$. B 81330235, propietaria del otro 40\%, y la CM16 S.L., con CIF número B 41702573 poseedora del último $20 \%$, las cuales aparecen asociadas con el nombre de "Grupo DIDRA", con sede en la calle Príncipe de Vergara número 43 de Madrid, distrito postal 28001.

Al hilo de estos acontecimientos, el edificio, que ya era considerado desde 1963 "Edificio de Interés Artístico", pasa a ser considerado "Bien Patrimonial” en 2007,

25 Expedido en Utrera por Carlos Marín Albornoz, Registro de la Propiedad n ${ }^{\circ} .11$ de Sevilla, fecha 31 de octubre de 2002, documento de fecha 9/11/1998, tomado del tomo 3136, libro 188, fincha 7995, antes 5053.

26 Manuel Macías Bernal hizo el año de 2003 un informe de Inspección Técnica para la familia Duque de Estrada y Martorell para evaluar el deterioro del palacio en orden a su rehabilitación, indicando expresamente las partes más perjudicadas de sus estructuras y elementos decorativos. Nuestra más cordial gratitud al profesor Manuel Macías Bernal por todos los documentos técnicos que nos ha facilitado en relación con la inspección técnica del palacio Villapanés.

27 Estos datos se certifican en un pleito de demanda ordinaria contra Juan Antonio, Pilar, María, Rosario y José Duque de estrada y Martorell, presentada por D. Francisco José Parada Vázquez en autos de juicio ordinario, con fecha en Sevilla 17 de junio de 2002. 
siendo introducido en esa fecha dentro del Catálogo General del Patrimonio Histórico Andaluzenelsectorde "otras edificacionesmonumentales ${ }^{28}$ ",y sometidoalaprotección pertinente del Plan Especial de Protección del Conjunto Histórico de Sevilla. ${ }^{29}$

El edificio, que ha sido definitivamente transformado en hotel de cuatro estrellas $^{30}$, según el catastro, se levanta sobre dos parcelas, que son en primer lugar la de la calle Santiago $n^{\circ} 31$, donde se ubica lo que conocemos como el Palacio Villapanés, y en segundo lugar la que despega en forma de quilla a la calle Ave María 4 a la que se accedía a través del jardín por medio de un callejón adosado al edificio colindante.

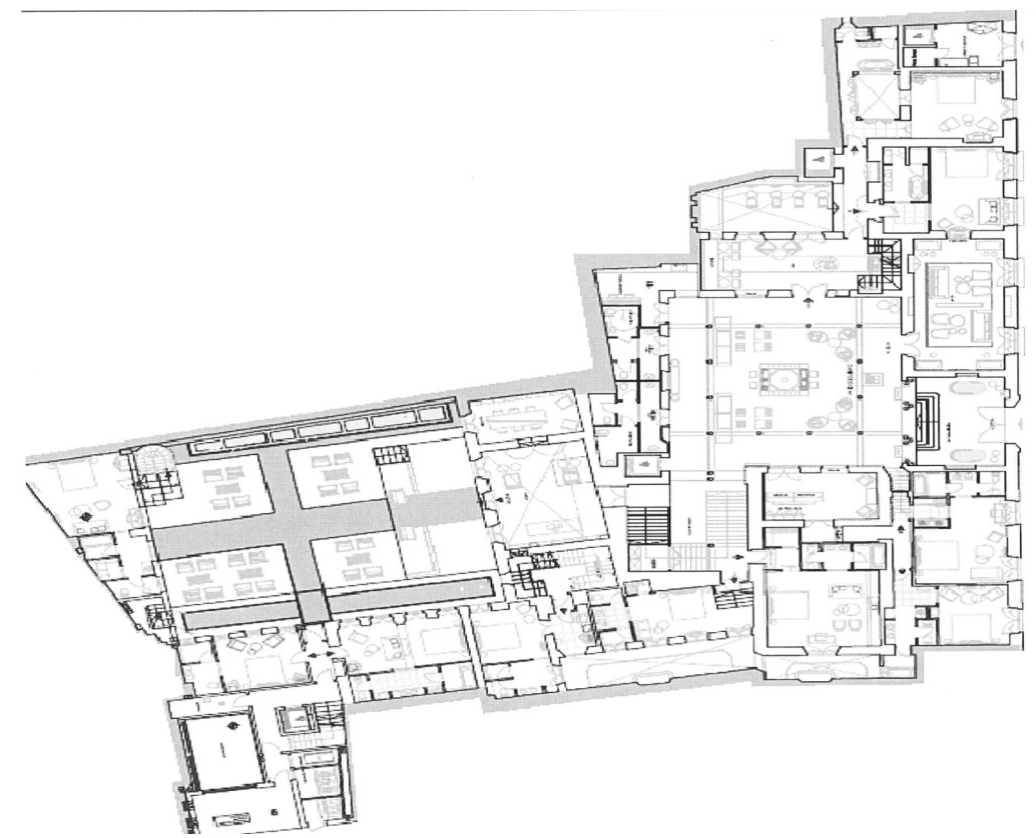

Fig. 6. Estado actual de la planta después de la rehabilitación. Arturo Tarancón Pradales Proyecto Básico de Rehabilitación en calle Santiago 31 y Proyecto Básico de Nueva Planta en calle Ave María $4^{31}$.

28 El inmueble llamado Palacio Villapanés, sito en la calle Santiago 31, esquina Ave María 4, se incluye dentro de "otras edificaciones monumentales", con la tipología de Casa Señorial perteneciente a la Arquitectura Residencial con código 01410910066, de carácter arquitectónico en la provincia de Sevilla, municipio de Sevilla con una actividad tipo residencial que pertenece a la tipología de Casas Palacio de la Edad Moderna de cronología 1700/1799 de estilo Barroco. Ya en 1963 estaba catalogada como Casa de importancia Artística y dentro del Plan General de Ordenación Urbanística.

29 El Ayuntamiento de Sevilla el año 2010 establece un Plan Especial de Protección del sector Santa Catalina Santiago.

30 Se exigió un proyecto que acatara la Ley 14/2007 de conservación patrimonial, incluyendo la metodología a aplicar (López, 2008)

31 Nuestra más cordial gratitud al arquitecto Arturo Tarancón Pradales, por todos los planos y documentos técnicos que nos ha facilitado en relación con la rehabilitación del palacio Villapanés. 


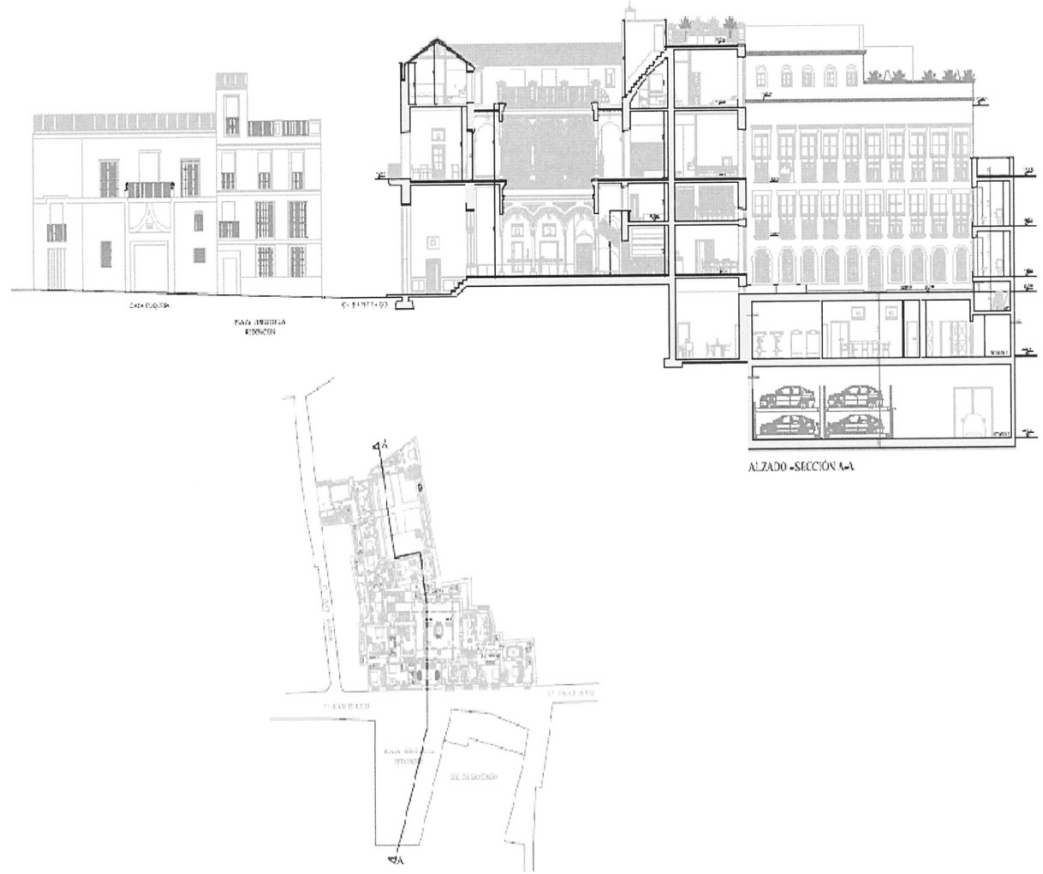

Fig. 7. Estado actual de la planta después de la rehabilitación. Sección longitudinal por jardín. Arturo Tarancón Pradales Proyecto Básico de Rehabilitación en calle Santiago 31 y Proyecto Básico de Nueva Planta en calle Ave María 4.

Cuando definitivamente, la licencia de ocupación fue concedida el 28 de julio del año $2010^{32}$, el entramado seguía sin retranquearse un milímetro de la planta original del siglo XVIII, apareciendo incluso la misma distribución que se conocía entonces entre las calles Santiago, Ave María y Azafrán, lo que además explicaría entre otras cosas la extraordinaria conservación del irregular y laberíntico entramado urbanístico medieval que se observa en el centro de Sevilla.

\section{GONCLUSIONES}

El deseo de pervivencia de las élites, que se manifiesta en un continuado hábito de conservación familiar (Martínez, 1996, p.25) transmitido de generación en generación y que se vincula al apego hacia la morada paterna, es un rasgo característico de las viviendas más notables del centro de Sevilla. En la actualidad

32 La Gerencia de Urbanismo del Ayuntamiento de Sevilla, en su Registro General, y con expediente 1437/2004 L.U. (3315=2009) AB/MVSA, concede una licencia de ocupación del hotel con fecha 28 de julio de 2010. 
encontramos el mismo sentimiento en la mentalidad colectiva. Así lo demuestra el hotel Villapanés, que sigue siendo una Casa Señorial dieciochesca, en sus aspectos lineal, visible hacia la calle y eficiente para los negocios de un comerciante, pero, que, sin salir de los gustos tradicionales entorno a un patio, llevó a estudiosos como Enrique Soria Mesa a hablar de cambio inmóvil (Soria Mesa, 2000).

En este sentido, el edificio, cómo todos los suntuosos, no se concibió de otro modo que, para integrarse socialmente, pervivir en el tiempo y en la memoria, de ahí que Diego Antonio Díaz se permitiera construirlo moderno, pero aprovechando algunas partes, y la misma distribución que tenía en 1699. De este modo, establecer los espacios con una sencilla modulación matemática abierta, y adecuar un eje de profundidad frente a la portada exterior, no rompía con el pasado, sino que le daba plenitud, en orden a paliar la sensación de "usurpación" o conciliar el cierto "resentimiento" vecinal de la zona.

Si a esto añadimos que la casa Villapanés se reconoce expresamente con el título de "palacio", no en virtud de la residencia de un marqués sino de un monarca: el rey de Baeza Abdelmán, efectivamente la sensación de inmovilidad es concebida en base a una supervivencia física y social que se remonta al siglo XIII. Este aspecto, que sienta las raíces de legitimación dinástica de la vivienda, es el que le otorga el derecho de mantener y usar el término "palacio" reservado exclusivamente a las moradas de estirpe real.

De hecho, hoy en día pasa lo mismo cuando en la rehabilitación del año 2012, el grupo DIDRA decide una explotación de la faceta aristocrática y piensa en una colectividad, que pueda sentirse atraída por este reclamo. Para ello, no sólo mantiene el término "palacio" como tal, sino que lo guarda como parte esencial de su publicidad, al igual que el escudo nobiliario de la escalera es memoria de los marqueses que lo habitaron.

De este modo el artículo pretende presentar no sólo unos hechos, sino las bases sobre las que se asientan, dar razones de su verdadera dimensión y el lugar que ocupan en la valoración de cualquier objeto. Así la perspectiva histórica presenta una correspondencia entre el aprecio del inmueble y sus propietarios que es fácilmente equiparable a cualquier mejora técnica o inversión ${ }^{33}$. En este caso, el alcance de su linaje es reconocimiento y aprecio de las personalidades que lo habitaron. De ahí que pasearse por el eje portada-patio, privilegio sólo reservado antiguamente a los grandes señores, sea restablecer la memoria del pasado histórico de Sevilla que mantiene con sus adecuaciones el hotel de cinco estrellas.

33 En este caso los autores como Kornstange (2007, p. 3) se inclinan hacia una concepción de patrimonio que tiene que ver con la posibilidad de almacenamiento y administración propia de las sociedades capitalistas o más precisamente con esa capacidad de restaurar, conservar y almacenar objetos de valor. 
A la hora de considerar una rehabilitación, los poderes públicos y privados deben involucrarse con el mismo interés histórico, para encontrar vías de conciliación dentro del sentimiento de apego a lo propio. Este es un aspecto digno de tener en cuenta de cara al futuro de la conservación, pues preservar, y hacerlo bien, no será más un ejercicio que languidece en espera de satisfacción económica, sino fruto de un deseo de continuidad histórica. El porvenir de los bienes catalogados (y no catalogados), en referencia a la acumulación de objetos que se unen en una pertenencia común al pasado como indicaba Choay, (1995), conlleva el todo. Los factores, como la ascendencia nobiliaria del inmueble, el desencuentro entre los intereses de la parcela, así como las características artísticas, no deben dejar de mirarse en lo que significa salvaguarda a nivel global.

\section{BIBLIOGRAFÍA}

Bonet Correa. Antonio (2011) Arquitectura y arquitectos en la Real Academia. Boletín de la Real Academia de Bellas Artes de San Fernando, n. 112-113, pp. XLVII-LII.

Cádenas y Vicent, Vicente de (1976). La blanca de la carne en Sevilla. Instituto Salazar y Castro (CSIC). Madrid: Hidalguía.

Choay, François (1995). Allegorie du Patrimoine. París: Seuil.

Clavero Salvador, Bartolomé (1976). Mayorazgo y propiedad feudal en Castilla: 13691836. Sevilla: Siglo XXI.

Chueca Goitia, Fernando (2001). Historia de la arquitectura española. Tomo II: Edad Moderna, Edad Contemporánea. Ávila: Fundación Cultural Santa Teresa.

Ezquiaga Domínguez, José María (1990). Normativa y forma de la ciudad: la regulación de los tipos edificatorios de la ordenanza de Madrid. Tesis doctoral. Madrid: Escuela Técnica Superior de Arquitectura (UPM).

Falcón Márquez, Teodoro (2012). Casas Sevillanas desde la Edad Media hasta el Barroco. Sevilla: Maratania.

Korstange, Maximiliano (2007). Tratado turístico. Eumed (en línea). Disponible en https://www.eumed.net/ libros 2007.

Kostof. Spiro (1988). Historia de la arquitectura. Madrid: Alianza Forma, t. 3

Lázaro Muñoz, María del Prado (1988). El arquitecto sevillano Diego Antonio Díaz. Sevilla: Monte de Piedad y Caja de Ahorros de Sevilla.

León Tello, Francisco José y Sanz Sanz, María Virginia (1994). Teoría de la construcción. Madrid: CSIC.

López Reche, Guillermo (2008). Ley 14/2007 de 26 de noviembre de Patrimonio Histórico de Andalucía, primera aproximación. Sevilla: Dirección General de Bienes Culturales, Consejería de Cultura de la Junta de Andalucía.

López Serena, Rocío y Vera Reina, Manuel (1998). Intervención arqueológica preventiva en el inmueble de la Calle Santiago número 31. Antiguo palacio de los marqueses de Villapanés y Torreblanca. Manuscrito. Archivo particular. Sevilla. 
López Serena, Roció y Vera Reina, Manuel (2010). Intervención Arqueológica Preventiva en el inmueble de la C/ Santiago, 31 de Sevilla. Antiguo Palacio de los Marqueses de Villapanés y Torreblanca. Anuario Arqueológico de Andalucía 2005, p. 31883200.

Macías Bernal, Manuel (2003). Inspección Técnica de Edificación del palacio Villapanés. Archivo particular. Sevilla

Martínez López, David (1996). Tierra, herencia y matrimonio: un modelo sobre la formación de la burguesía agraria andaluza siglos XVIII-XIX. Jaén: Universidad de Jaén, p. 25.

Martínez Sánchez, María del Carmen (2008). El protocolo como herramienta estratégica de comunicación. Una constante histórica y estudio de casos actuales. Sevilla: Universidad de Sevilla.

Molina Recio, Raúl (2011). "El largo camino hacia el individualismo. El palacio de los condes de Luque en Granada en los inicios de la contemporaneidad. Revista Historia y Genealogía, n. 1, pp. 57-111.

Ollero Lobato, Francisco (2005). Arquitectura doméstica en Sevilla durante la segunda mitad del XVIII. Atrio, n. 10-11, pp. 113-123.

Ollero Lobato, Francisco (2012). Arquitectura doméstica en Sevilla durante la segunda mitad del XVIII. Atrio, n. 18, pp. 27-42.

Ortiz de Zúñiga, Diego (1796). Annales Eclesiásticos y seculares de la muy noble y muy leal, ciudad de Sevilla. Sevilla: Imprenta Real.

Pleguezuelo, Antonio (1982). Sobre Cayetano de Acosta, escultor en piedra. En: Arte Sevillano 2. Sevilla: Caja de Ahorros Provincial de San Fernando. p. 28.

Ponz, Antonio (1972). Viage de España, en que se da noticia de las cosas mas apreciables, $y$ dignas de saberse que hay en ella. Ed. facsímil, Madrid: Viuda de Ibarra, 1787. Madrid: Atlas, t. IX.

Rodríguez Ruiz, Delfín (1992). Imágenes de lo posible: los proyectos de arquitectura premiados por la Real Academia de Bellas Artes de San Fernando 1753-1831. Madrid: Consejería de Educación y Cultura: Real Academia de San Fernando: Dirección General de Patrimonio Cultural de la Comunidad de Madrid.

Roig del Negro, Álvaro (2001). La Real Fundición de Cañones de Sevilla, historia, arquitectura y urbanismo de una fábrica del siglo XVIII. Tesis doctoral. Universidad de Sevilla.

Sancho Corbacho, Antonio (1984). Arquitectura barroca sevillana del siglo XVIII. Madrid: Consejo Superior de Investigaciones Científicas (CSIC).

Sanz y Sanz, José (1992), Marco Vitruvio Polión, los Diez Libros de Arquitectura. Madrid: Akal.

Soria Mesa, Enrique (2000). El cambio Inmóvil. Transformaciones y permanencias en una élite de poder (Córdoba, S. XVI-XIX). Córdoba: La Posada. 
Los orígenes del Hotel Villapanés, la semblanza... - Isabel Corripio Gil-Delgado

Tapias Herrero, Enrique (2015). El teniente general don Manuel López Pintado (16771745): ascenso económico y social de un comerciante y marino en la Carrera de Indias. Sevilla: Universidad de Sevilla.

Tarancón Pradales, Arturo (2010). Proyecto Básico de Rehabilitación en calle Santiago 31 y Proyecto Básico de Nueva Planta en calle Ave María no 4. Manuscrito.

Urquízar Herrera, Antonio (2001). El Renacimiento en la periferia, la recepción de los Modos Italianos en la experiencia pictórica del Quinientos Cordobés. Córdoba: Estudios de Historia Moderna.

Vázquez Consuegra, Guillermo (1988). Cien edificios sevillanos susceptibles de rehabilitación. Sevilla: Consejería de Obras Públicas y Transporte, Junta de Andalucía.

\section{Documentos consultados}

Permuta de tributo perpetuo a la fábrica de Santiago y Baltasar Crespo. Protocolo Notarial P-5190 (1727). AHPSE (Sevilla), p. 180

Venta de Casas de Jacinto Serrano e hijos a Manuel López Pintado. Protocolo Notarial P-14138 (1746). AHPSE (Sevilla), pp. 171-181.

Escrituras propiedad palacio Villapanés. A.V. Sector Torreblanca, Atado VI/I. Sevilla: años: 1483 , pp. $68-69 ; 1580$ p. $69 ; 1608$, p. $70 ; 1679$, p. $75 ; 1728$ pp. $1-10$

Escritura casas del Marqués de Castellón Sector Torreblanca, Atado VI/I (1726). Sevilla: A.V, pp. 1-96;

Escritura de venta de un pedazo de sitio del convento correspondiente a lavadero y cocina del convento de N. Sra. De los Reyes que linda con las casas principales de Manuel López Pintado. Sector Torreblanca, Atado VI/I (1727). Sevilla: A.V., p. 180

Venta de casas de la parroquia de Santiago el Viejo Sector Torreblanca, Atado VI/I (1727). Sevilla: A.V. pp. 1-13.

Venta de Casas de Jacinto Serrano e hijos a Manuel López Pintado. Sector Torreblanca, Atado VI/I (1728). Sevilla: A.V., p. 526.

Venta de Casas Sector Torreblanca, Atado VI/I (1739). Sevilla: A.V. p. 24.

Memoria Histórico-arquitectónica de las Descalzas Reales, antiguo convento de Santa María de los Reyes. Sevilla (2012): Consejería de Fomento y Vivienda, Junta de Andalucía.

Propiedad número P.7995, asiento 49/191 (1998), Sevilla: Registro de la Propiedad de Sevilla 11.

Expediente 1437/2004 L.U.(3315=2009) AB/MVSA. Sevilla: Registro General Gerencia de Urbanismo, Ayuntamiento de Sevilla.

Ordenanzas del Plan Especial de Protección del conjunto histórico de Sevilla, Art. 10.4 título 1. sector 4 Santa Catalina-Santiago (2010). Sevilla: Excmo. Ayuntamiento de Sevilla, Servicio de Planeamiento, Gerencia de Urbanismo, p. 12. 